\title{
LA ECONOMÍA MUNDIAL, LAS TENSIONES CAMBIARIAS Y LA POLÍTICA MONETARIA RECIENTE EN CHILE*
}

\author{
José De Gregorio
}

\begin{abstract}
Resumen: Este documento discute los riesgos y tensiones que han emergido en la economía global por las características del actual proceso de recuperación mundial, vigoroso en las economías emergentes y lento en las desarrolladas, y sus implicancias en la economía chilena. Se revisan las dificultades de las economías avanzadas para impulsar su débil recuperación, los problemas de deuda pública en Europa, los elevados precios de las materias primas y los síntomas de sobrecalentamiento de algunas emergentes. Este escenario ha llevado a que los tipos de cambio de las economías emergentes estén en los menores niveles de la última década. Se explican las características de la intervención cambiaria en Chile y se describen las diferencias en materia de flujos de capitales en Chile respecto de otros países y episodios de
\end{abstract}

José De Gregorio. Doctor en Economía, Massachusetts Institute of Technology (MIT). Presidente del Banco Central de Chile.

* Presentación en el Club Monetario, Universidad Finis Terrae, Santiago, 20 de mayo de 2011. Agradezco los valiosos comentarios y sugerencias de Kevin Cowan, Luis Óscar Herrera y Enrique Orellana. Dados los cambios del escenario macroeconómico de los últimos meses he agregado un post-scriptum al final del documento. 
flujos importantes a economías emergentes. También se discuten las medidas recientes de política monetaria y se sugiere que hoy el nivel de la TPM neutral probablemente sea más bajo que las estimaciones previas, influida por el entorno internacional de bajas tasas de interés.

Palabras clave: economía mundial, flujos de capitales, intervención cambiaria, política monetaria.

Recibido: junio 2011; aceptado: julio 2011.

\title{
THE WORLD ECONOMY, EXCHANGE TENSIONS AND RECENT MONETARY POLICY IN CHILE Jose de Gregorio
}

\begin{abstract}
This article discusses the risks and tensions that have emerged in the global economy given the characteristics of the present world recovery, vigorous in emerging economies and slow in the developed ones, and their implications on the Chilean economy. The difficulties faced by advanced economies in pushing their weak recovery are reviewed, as are the problems of public debt in Europe, the high prices of raw materials and the signs of overheating in some emerging economies. This scenario has led exchange rates in emerging economies to be at their lowest levels in the past decades. The characteristics of exchange intervention in Chile are explained and the differences in the capital flows in Chile are described as compared to other countries, together with episodes of important flows to emerging economies. Also discussed are the recent monetary policy measures and it is suggested that today, the level of a neutral MAR is probably lower than prior estimations, influenced by the internationally low interest rates.
\end{abstract}

Keywords: world economy, capital flows, exchange intevention, monetary policy.

Received: June 2011; accepted: July 2011. 
Agradezco la invitación a presentar en el Club Monetario de la Universidad Finis Terrae. Esta es una buena oportunidad para revisar algunos desarrollos recientes de la economía chilena, en particular la evolución del tipo de cambio, la intervención cambiaria que estamos llevando a cabo, y nuestras decisiones de política monetaria. Pero antes de entrar en dichos temas quisiera revisar algunos elementos importantes del escenario internacional, el cual es el origen de los principales riesgos y tensiones por los que atraviesa nuestra economía.

\section{La economía internacional}

La economía global se está recuperando de la Gran Recesión. Esta recuperación, sin embargo, ha sido heterogénea y está sujeta a riesgos. Las economías desarrolladas aún no pueden superar del todo los efectos negativos de la crisis, mientras que las economías emergentes se encuentran en una sólida senda de crecimiento. Esto, pese a que no habiendo caído en los excesos financieros de las economías avanzadas, igualmente sufrieron las consecuencias de la crisis. Con todo, la magnitud del impacto en el crecimiento de las economías emergentes fue menor de lo que se habría esperado dada la historia, siendo además capaces de recuperarse con rapidez y vigor (Gráfico $\mathrm{N}^{\circ} 1$ ).

El positivo desempeño de las economías emergentes se funda en sus esquemas de políticas macroeconómicas. Estos han evolucionado y mejorado a lo largo del tiempo, en parte por el aprendizaje que dejaron un sinnúmero de crisis que sufrimos, cuyo origen estuvo en desbalances macroeconómicos y financieros. Estos esquemas contemplan una inflación baja y estable, finanzas públicas saludables, sistemas financieros sólidos y bien regulados, y un tipo de cambio realista. Por supuesto que el marco de políticas difiere entre países, pero los principios básicos son comunes. En Chile, una política fiscal que ahorra en tiempos de bonanza, un Banco Central autónomo con una política monetaria conducida bajo un esquema de metas de inflación y un tipo de cambio flexible, fueron claves para afrontar con éxito la crisis. Se agrega un sistema financiero sólido y bien regulado, donde no están permitidas muchas de las operaciones que llevaron a otras economías a la situación actual. En la banca domina un modelo de banca tradicional en el cual una sólida 


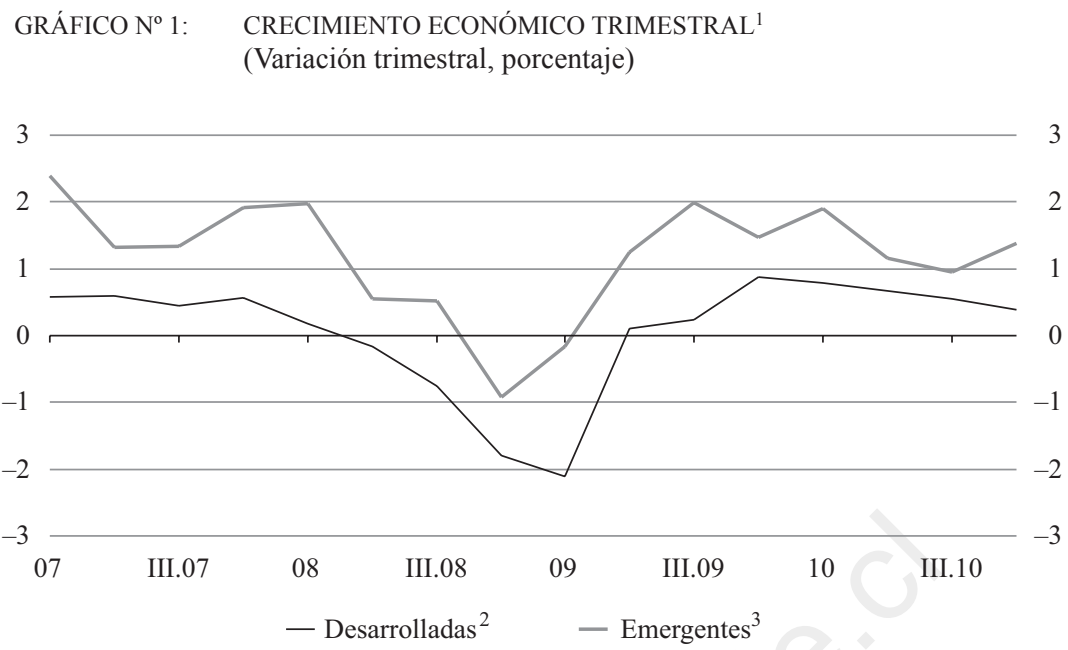

${ }^{1}$ Regiones ponderadas a PPC.

2 Considera Australia, Canadá, Dinamarca, EE.UU., Japón, Nueva Zelanda, Reino Unido, Suecia, Suiza y Zona Euro.

${ }^{3}$ Considera Argentina, Brasil, Bulgaria, Chile, China, Colombia, Filipinas, Hong Kong, India, Indonesia, Malasia, México, Perú, Rep. Corea, Rep. Checa, Rusia, Singapur, Sudáfrica, Tailandia, Taiwán, Turquía y Venezuela.

Fuentes: Banco Central de Chile en base a oficinas de estadísticas de cada país y Fondo Monetario Internacional.

base de depósitos, minoristas e institucionales, permite financiar principalmente créditos.

Previo a la crisis se habló mucho del desacoplamiento del crecimiento de las economías emergentes respecto de las desarrolladas. Esta idea, que tomó fuerza en el curso del 2007 y 2008, fue seriamente cuestionada durante la crisis, pues, como lo mencioné, nadie escapó de sus efectos. No obstante, visto en perspectiva, se puede afirmar que efectivamente hubo desacoplamiento. Es cierto que en un mundo globalizado las interconexiones comerciales y financieras impiden a las economías aislarse del ciclo global, pero el desempeño de las economías emergentes muestra que es posible atenuar las consecuencias negativas del ciclo externo. De hecho, es difícil encontrar otro episodio en el cual las economías desarrolladas hayan tenido una severa recesión que no se haya magnificado en los países en desarrollo. Esto es particularmente relevante en América Latina (Gráfico No 2). 
GRÁFICO N ${ }^{\circ}$ 2: CRECIMIENTO MUNDIAL*

(Variación anual, porcentaje)

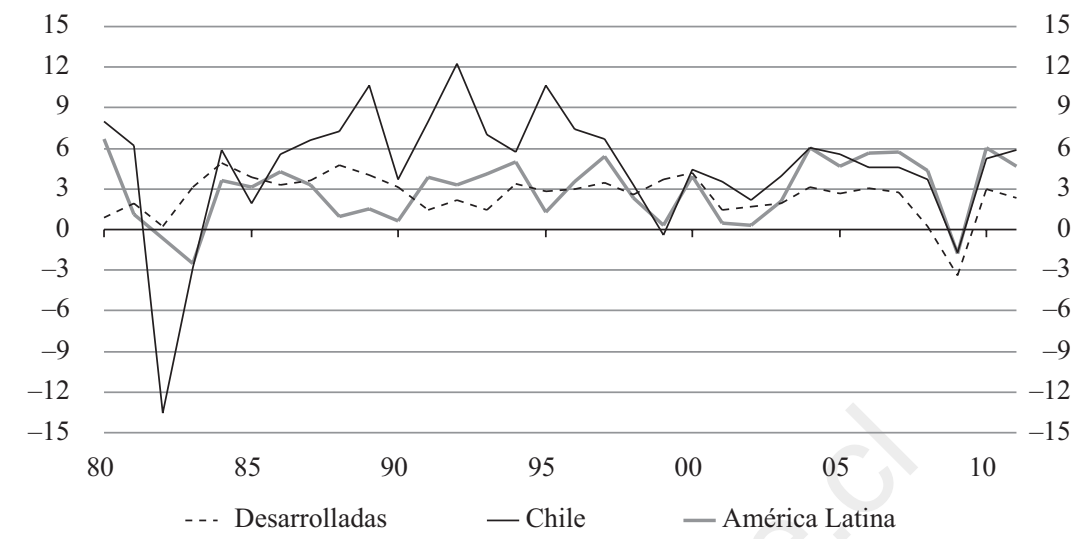

* Área gris corresponde a la proyección del WEO de abril del 2011.

Fuente: Fondo Monetario Internacional.

Las economías desarrolladas están en un escenario distinto. Enfrentan importantes dudas sobre la sostenibilidad de su situación fiscal. Las fuertes expansiones del gasto fiscal previas a la crisis y la implementación de inéditos paquetes de estímulo para enfrentarla llevaron sus niveles de deuda a cifras muy elevadas. Hoy no tienen más espacio para seguir aumentando el tamaño del gasto público y aun más necesitan de un ajuste importante, difícil de implementar ante la débil situación de sus economías. Los casos de Estados Unidos y Japón son bastante claros al respecto. Se suma lo que sucede en las economías periféricas de Europa, los ajustes que requieren y las tensiones financieras que enfrentan a partir de ello. Los fundadores del euro tenían en mente que las economías de Europa, en particular las del sur, adoptarían buenas políticas macroeconómicas, siguiendo el ejemplo de Alemania. No obstante, parece que algunas economías, por ejemplo Grecia, lo único que aprovecharon fueron bajas primas de riesgo. Ello les permitió un masivo endeudamiento público, alcanzando niveles de déficit muy por encima de los establecidos en el Pacto de Estabilidad y Crecimiento. Esto los ha dejado en una situación de extrema vulnerabilidad financiera, que hoy se ve compleja de resolver. 
Por el momento, los riesgos parecen estar contenidos, pero la falta de credibilidad de los mercados ha llevado a algunos agentes a especular con la posible salida de algún país del euro. Esto es algo que parece imposible, pues su ocurrencia podría provocar una gran crisis financiera. Esta situación la tienen muy clara las autoridades en Europa. Mucho se podrá discutir si fue oportuno o no admitir a tal o cual país, pero una vez dentro y en una situación tan frágil como la actual, la decisión se torna irreversible.

En todo caso, los problemas de deuda pública en Europa son complejos y se requiere de una solución global y más permanente. De acuerdo con las proyecciones contenidas en la tercera revisión del acuerdo stand-by de Grecia con el FMI, desde aquí al 2020 Grecia debe generar un superávit fiscal primario de 6 por ciento del PIB por año. Ello llevaría su deuda pública desde los niveles actuales de en torno a 1,5 veces el PIB a cifras de 1,3 veces. Esto es un gran ajuste si consideramos que en el 2008 este país tuvo un déficit primario de 4,5 por ciento del PIB. Además, todo esto bajo el supuesto de que paga una tasa de interés entre 6 y 7 por ciento, en circunstancias que hoy la tasa de mercado se ubica en torno a 18 por ciento. Ciertamente si estas tasas no bajan será difícil pensar que Grecia vuelva a tener un acceso fluido a los mercados privados de deuda, tan difícil como creer en un financiamiento permanente por parte de las agencias oficiales. Esta encrucijada lleva a buscar otras soluciones de carácter permanente, que permitan recobrar la solvencia fiscal y distribuir pérdidas sin atentar contra la estabilidad financiera.

Otra arista compleja de la situación en las economías desarrolladas es la debilidad de su recuperación. Más allá de que estabilizaron los sistemas financieros y la actividad comenzó a repuntar, no han logrado reducir de manera relevante sus altas tasas de desempleo y aún mantienen elevadas holguras de capacidad (Gráfico $\mathrm{N}^{\mathrm{o}} 3$ ). Además, las perspectivas de crecimiento son moderadas y como hemos visto en las últimas semanas, cada dato que se conoce puede imponer una volatilidad importante sobre la evaluación que el mercado hace sobre la fortaleza de la recuperación.

Su fragilidad financiera además hace difícil que puedan sostener una recuperación muy vigorosa. La situación financiera de hogares y gobiernos es compleja dado el alto endeudamiento en que se encuentran. De ahí que resulta poco probable pensar que su demanda interna 


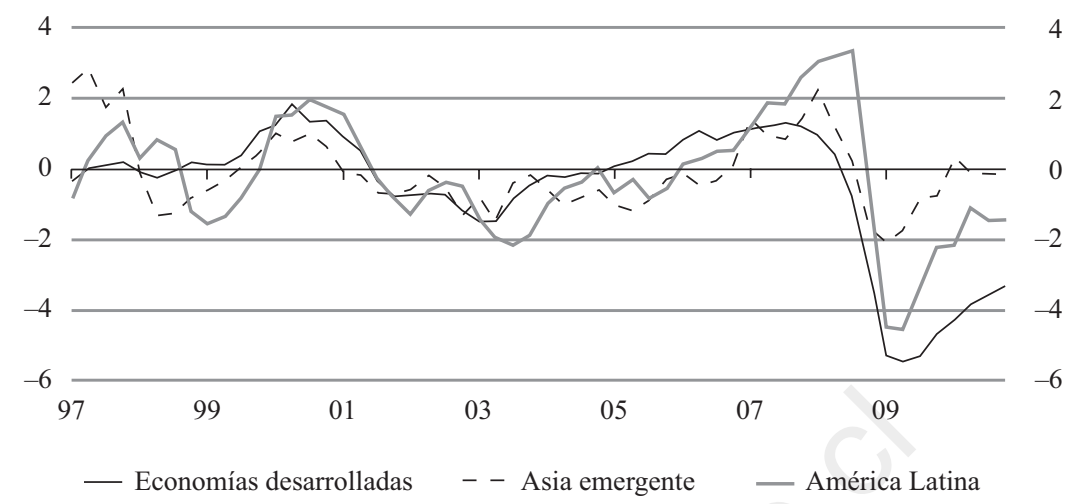

* Se utilizan las estimaciones de la OCDE para las brechas de producto de las economías desarrolladas. Para el resto de las regiones, las brechas de producto se obtienen utilizando un filtro HP.

Fuentes: Banco Central de Chile en base a Bloomberg, Consensus Forecasts, OCDE y oficinas de estadísticas de cada país.

será una fuente de expansión para la actividad. Por ello, la base para un mayor crecimiento está, por ahora, en la demanda que proviene del resto del mundo. La debilidad de sus monedas, y la mayor fortaleza de las monedas emergentes, es coherente con ello. En este ámbito se da otra paradoja. Alemania, el país más fuerte de la Unión Europea, a quien los países periféricos deberían seguir como ejemplo, ha sido uno de los mayores beneficiados en esta coyuntura. Su rigor fiscal y su fortaleza productiva como uno de los grandes proveedores de bienes de capital del mundo se han visto favorecidos por un euro relativamente débil. De no tener una moneda común con el resto de la anémica Europa, el marco alemán sería sin duda la moneda más fuerte del mundo. Bastante por arriba del equivalente a 1,4 dólares por euro. Su pertenencia a una unión monetaria frágil le ha reportado el beneficio de una moneda relativamente débil, lo que ha sido un factor importante en su rápida expansión actual.

Para sumar ingredientes al coctel que hoy vemos en la economía mundial, nos volvemos a enfrentar a un significativo incremento de los precios de las materias primas. Como siempre, es posible atribuirlo a 
diversos factores. Uno común es el rápido crecimiento de las economías emergentes y su consiguiente aumento en la demanda. A él se han agregado, entre otros, elementos climáticos que han afectado la producción de alimentos y riesgos geopolíticos que han impactado el precio del petróleo. Como resultado de estos mayores precios y de que las economías emergentes se encuentran cerca de su nivel de crecimiento potencial, algunas con claros síntomas de sobrecalentamiento, la inflación efectiva y sus perspectivas han aumentado en todo el mundo. Varias economías emergentes, entre ellas Chile, han quitado impulso monetario como respuesta a este ciclo. En cambio, las economías desarrolladas, con una débil recuperación, no solo han sostenido el fuerte estímulo monetario previo, sino que se espera que lo mantengan por un tiempo prolongado. Esta mezcla de desbalance de las políticas monetarias, elevados precios de las materias primas y buenas perspectivas de crecimiento en las economías emergentes ha generado tensiones cambiarias y flujos de capitales, temas a los cuales me referiré a continuación.

\section{Tipo de cambio y flujos de capital}

Previo a la crisis financiera, una parte de las economías desarrolladas, en particular Estados Unidos, estaban incurriendo en elevados déficit de cuenta corriente. Este gasto en exceso era financiado por un superávit en las economías emergentes. En particular, por China, con elevadas tasas de ahorro, y las economías exportadoras de petróleo (Gráfico $\mathrm{N}^{\circ} 4$ ).

Los desbalances globales fueron parte importante de las causas de la crisis. Esto no era muy distinto de lo vivido muchas veces en las economías emergentes: bajas tasas de ahorro, elevados déficit de cuenta corriente y un endeudamiento que se usaba para financiar consumo o expansiones fiscales insostenibles. En este caso, Estados Unidos experimentó una fuerte expansión del gasto y un elevado endeudamiento, el que fue a financiar la compra de casas sobrevaloradas. Como ya lo sabemos, y lo advertimos insistentemente antes de que se desatara la crisis, este conjunto tarde o temprano termina en severos ajustes.

Elevados términos de intercambio, entradas de capitales y altas tasas de crecimiento han resultado en apreciaciones del tipo de cambio en la mayoría de las economías emergentes y exportadoras de materias primas (Gráfico $\mathrm{N}^{\mathrm{o}} 5$ ). En términos reales, el nivel actual del tipo de 
GRÁFICO No ${ }^{\circ}$ : SALDO EN CUENTA CORRIENTE

(Miles de millones de dólares)

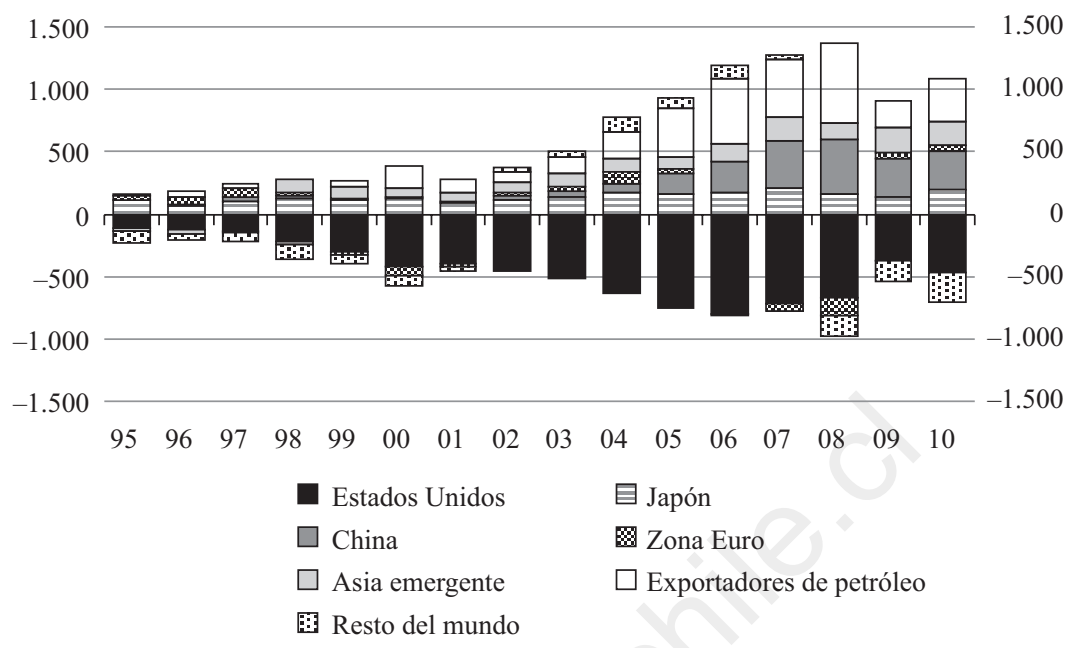

Fuente: WEO de abril del 2011, Fondo Monetario Internacional.

GRÁFICO N ${ }^{\circ}$ 5: $\quad$ TIPO DE CAMBIO NOMINAL MULTILATERAL ${ }^{1}$

(Índice $2005=100)$ )

140

130

120

An

110
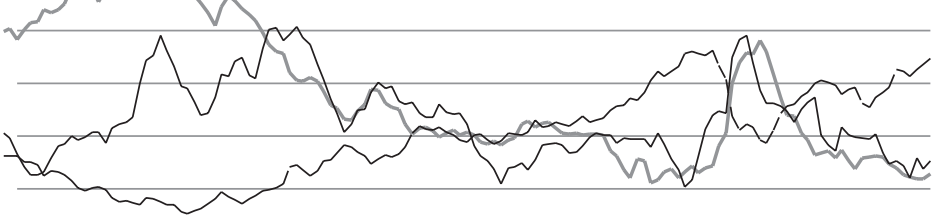

100

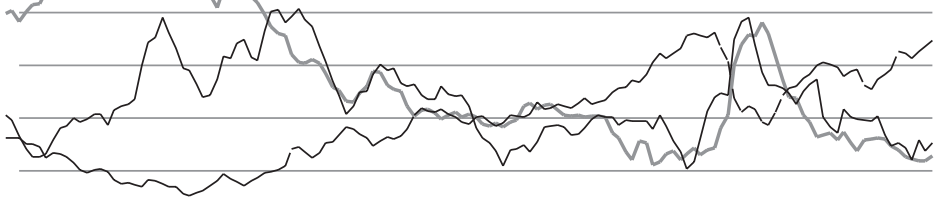

130

80

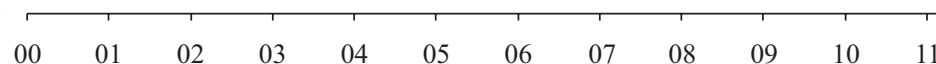

120

110

100

90

80

- - EE.UU. — Exp. de productos básicos ${ }^{2}$

- Chile

${ }^{1}$ Un aumento indica una depreciación de la moneda local.

2 Promedio simple de Australia, Nueva Zelanda y Canadá.

Fuente: Banco Internacional de Pagos (BIS). 
cambio está en sus menores niveles de la última década en gran parte de las economías emergentes (Gráfico $\mathrm{N}^{\circ}$ 6). La mayor fortaleza del crecimiento de estas economías emergentes fortalece también sus monedas. Lo contrario sucede en las economías desarrolladas.

Como lo mencioné previamente, los elevados niveles de endeudamiento en las economías desarrolladas ponen restricciones al crecimiento de su demanda interna. En cambio, en las economías emergentes el crecimiento de la demanda interna empieza a topar con restricciones de oferta interna, por lo que requieren de la reorientación de su demanda hacia bienes importados. El ajuste de la economía global necesita de un cambio en la composición de la demanda, el ajuste del tipo de cambio va en esa dirección. Es esperable que una vez que las economías desarrolladas recuperen su fortaleza, sus monedas también lo hagan. No obstante, esta transición puede ser prolongada. Aunque el ajuste es saludable para la economía mundial, existen tensiones que pueden requerir de políticas excepcionales.

GRÁFICO No 6: $\quad$ TIPO DE CAMBIO REAL

(Índice promedio ene. $00-$ mar. $11=100)$

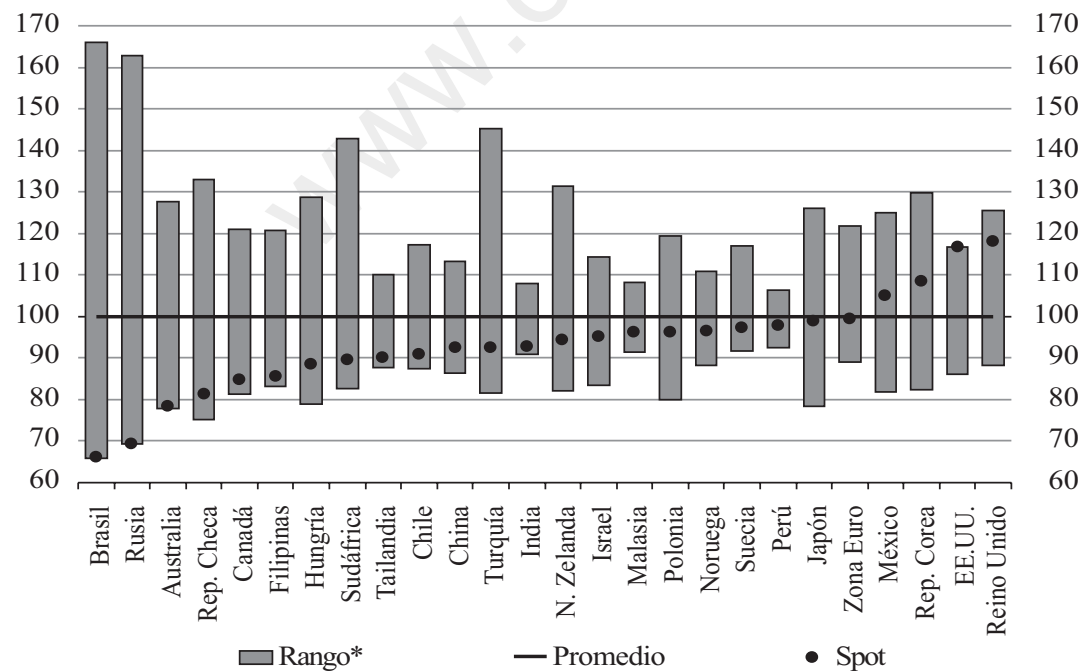

* El rango indica los valores máximos y mínimos que mostró la moneda local durante el período señalado.

Fuente: Banco Central de Chile en base a cifras del Banco Internacional de Pagos (BIS). 
Por lo anterior, varias economías emergentes, Chile entre ellas, han tomado medidas para mitigar los ajustes cambiarios. No obstante, dadas las fuerzas que lo determinan, resulta evidente que esta tendencia puede mitigarse, pero no revertirse por la sola acción de una medida unilateral. En enero, el Banco inició un significativo proceso de acumulación de reservas. Anunciamos la compra de 12 mil millones de dólares, lo que equivale a una acumulación de reservas del orden de 5 puntos del PIB, la mayor desde la primera mitad de los noventa (Gráfico $\mathrm{N}^{\mathrm{o}} 7$ ). Esta intervención es esterilizada, es decir, los pesos que se emiten para comprar dólares se retiran por la vía de emisión de deuda. De no hacer esto, el aumento de la liquidez sería incoherente con las decisiones de política monetaria. Esta se orientaría a un objetivo cambiario y dejaría de conducirse para cumplir con la meta de inflación. No creo necesario explicar por qué esto sería tremendamente perjudicial para nuestra economía.

El propósito de la intervención es doble. Por una parte, permite tener un mayor nivel de reservas, que a pesar de sus costos, son un buen seguro contra movimientos bruscos de los flujos de capital. Aunque la mayoría de las economías no usó mayormente sus reservas durante la

GRÁFICO N N $^{\circ}$ CAMBIO DE LAS RESERVAS INTERNACIONALES DEL BANCO CENTRAL DE CHILE

(Porcentaje del PIB)

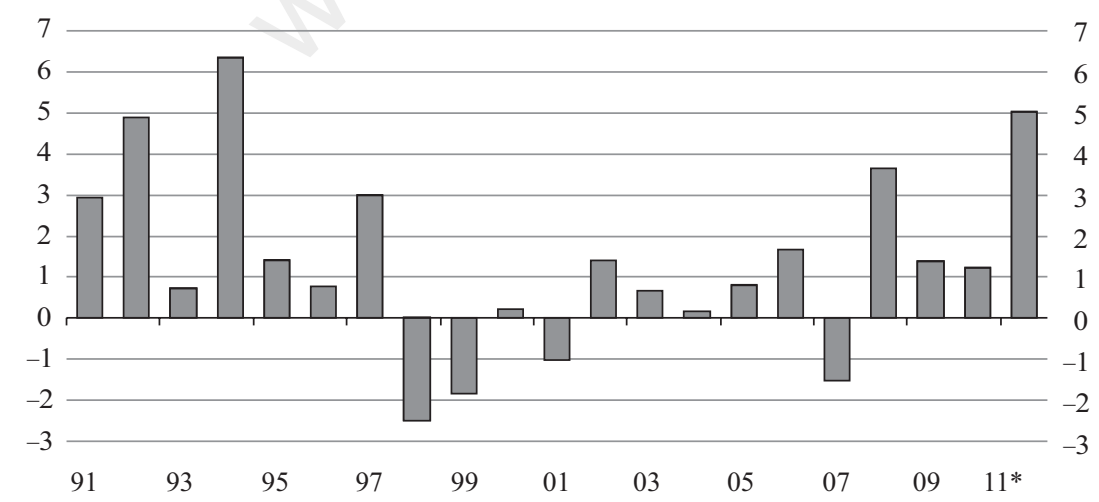

* Las reservas consideran la compra de los US\$12.000 millones que se anunció en enero de este año. Para el PIB se utilizan las proyecciones de crecimiento y de inflación estimadas en el IPoM de marzo.

Fuente: Banco Central de Chile. 
crisis, su sola existencia previene movimientos de capital desestabilizadores. Por otra parte, la intervención cambiaria mitiga los ajustes del tipo de cambio. Como hemos afirmado anteriormente, de no haberse producido la intervención, el peso hoy estaría más apreciado. En todo caso, vale la pena puntualizar que la apreciación del peso chileno no es muy distinta de la que se observa en un amplio conjunto de economías emergentes y exportadoras de materias primas que han aplicado o no medidas cambiarias.

Es importante volver a resaltar que la intervención cambiaria tiene solo efectos transitorios. No puede modificar de manera permanente la competitividad de una economía. Esto se consigue con políticas que afecten el lado real de la economía. Lo monetario-cambiario solo tiene efectos transitorios. El impacto de una intervención esterilizada sobre el tipo de cambio se da a través de la composición de los portafolios de monedas. En la medida que los activos financieros externos e internos no son perfectos sustitutos, los cambios en su oferta relativa tienen efectos sobre los precios, pero estos se deberían ir disipando en el tiempo. En su último Regional Economic Outlook del Hemisferio Occidental, el FMI da cuenta de estimaciones que muestran que las intervenciones reducen la tasa de apreciación de las monedas. Señala que sus efectos son menores en economías financieramente más abiertas. También que no hay mayores diferencias si las intervenciones se realizan en base a reglas o de manera discrecional. Nosotros la hacemos basados en una regla, para no perder el control sobre la política monetaria. Como esta evidencia muestra, no habría efectos muy distintos sobre el tipo de cambio si se hiciera de manera arbitraria. Esto no es sorprendente, ya que sus efectos dependen del monto de la intervención y de la composición de los portafolios de monedas.

A muchos les ha llamado la atención que con una medida similar a la aplicada durante el 2008, la evolución del tipo de cambio ha sido distinta. De más está decir que la mezcla de sucesos también ha sido distinta, en particular la evolución del entorno internacional. En ese entonces la economía mundial iba camino a una crisis severa y la aversión al riesgo en aumento. Esto redujo el valor de los activos de las economías emergentes y fortaleció el dólar. El cobre y los términos de intercambio comenzaron a caer. Hoy la situación es muy distinta, el dólar está en sus niveles de mayor debilidad y el cobre se ha mantenido en niveles muy elevados. Además, las perspectivas son que este se ubicará en niveles no muy alejados de los actuales (Gráfico $\mathrm{N}^{\circ} 8$ ). 


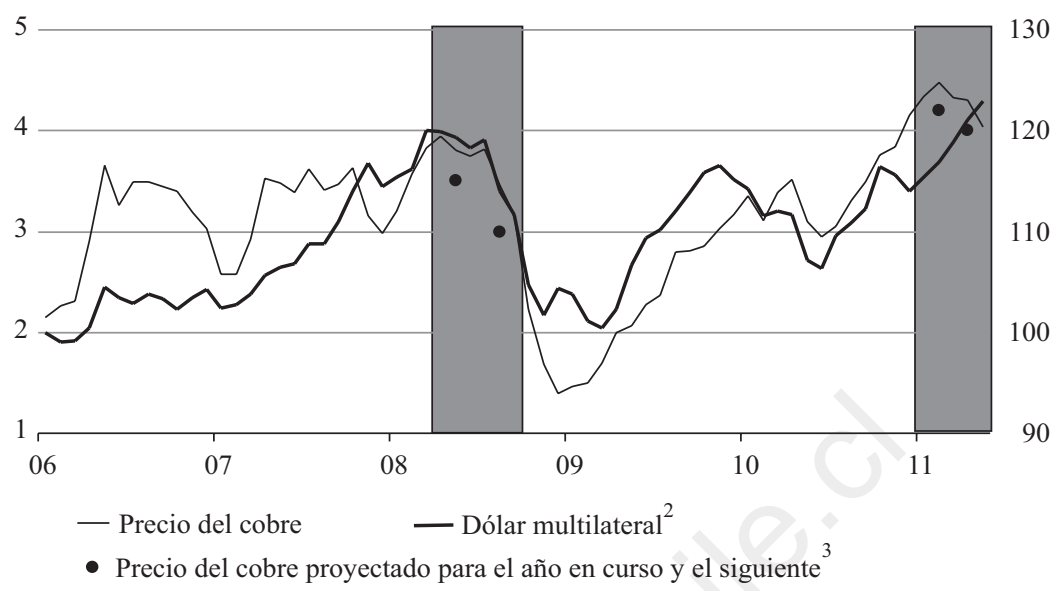

${ }^{1}$ Barras grises indican período de intervención cambiaria.

${ }^{2}$ Dólar respecto de una canasta de monedas de los principales socios comerciales de EE.UU. Un aumento indica una depreciación del dólar.

${ }^{3}$ En el IPoM de mayo del 2008 y el IPoM de marzo del 2011, respectivamente.

Fuentes: Banco Central de Chile, Bloomberg y Reserva Federal de Estados Unidos.

Otro asunto que ha cruzado la discusión respecto del tema cambiario es el efecto de los movimientos de capitales. Varias economías emergentes han visto un importante aumento de los influjos de capital, lo cual ha agregado presión sobre sus monedas. Sin embargo, es importante destacar que este no es un fenómeno generalizado, en la medida que los déficits en cuenta corriente se mantienen relativamente acotados. En el conjunto de economías emergentes, hoy las entradas de capitales son similares a las de mediados de los noventa y ciertamente menores a las observadas en el período 2006-2008. No obstante, el flujo de salida de capitales desde estas economías es ampliamente mayor que en los noventa, provocando un saldo neto cercano a cero (Gráfico $\left.\mathrm{N}^{\circ} 9\right)$.

Chile no es muy distinto, con saldos netos incluso negativos (Gráfico $\mathrm{N}^{\mathrm{o}} 10$ ). Por lo demás, las condiciones estructurales de la economía chilena y el marco de políticas económicas son muy distintas de las que prevalecían en los noventa. Como muestra, la tasa de interés 
GRÁFICO N 9: $\quad$ FLUJOS DE CAPITALES PROMEDIO DE PAÍSES EMERGENTES* (Porcentaje del PIB)

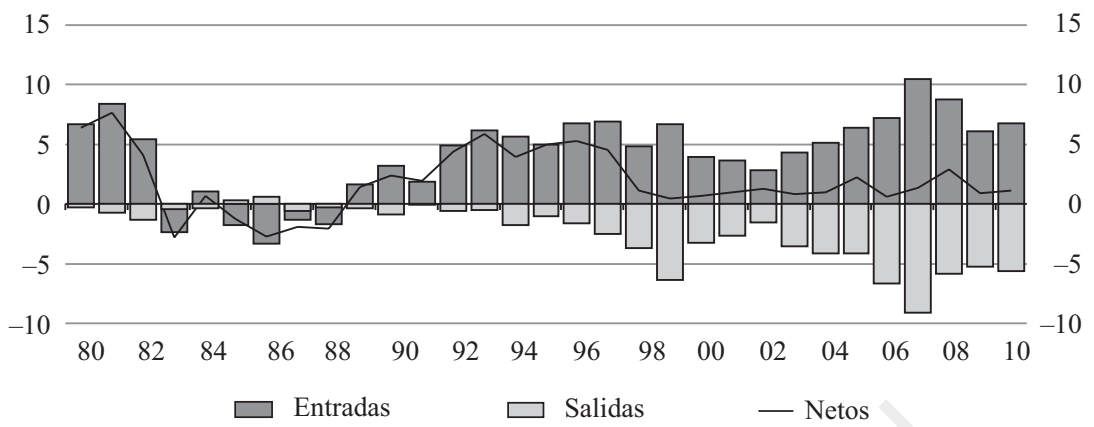

* Incluye Brasil, Chile, China, Colombia, Egipto, Filipinas, Hungría, India, Indonesia, Israel, Malasia, Marruecos, México, Perú, Polonia, Rep. Corea, Rusia, Sudáfrica, Tailandia, Taiwán y Turquía.

Fuente: Banco Central de Chile en base a Fondo Monetario Internacional.

\section{GRÁFICO No 10: FLUJOS DE CAPITALES EN CHILE*}

(Porcentaje del PIB)

20

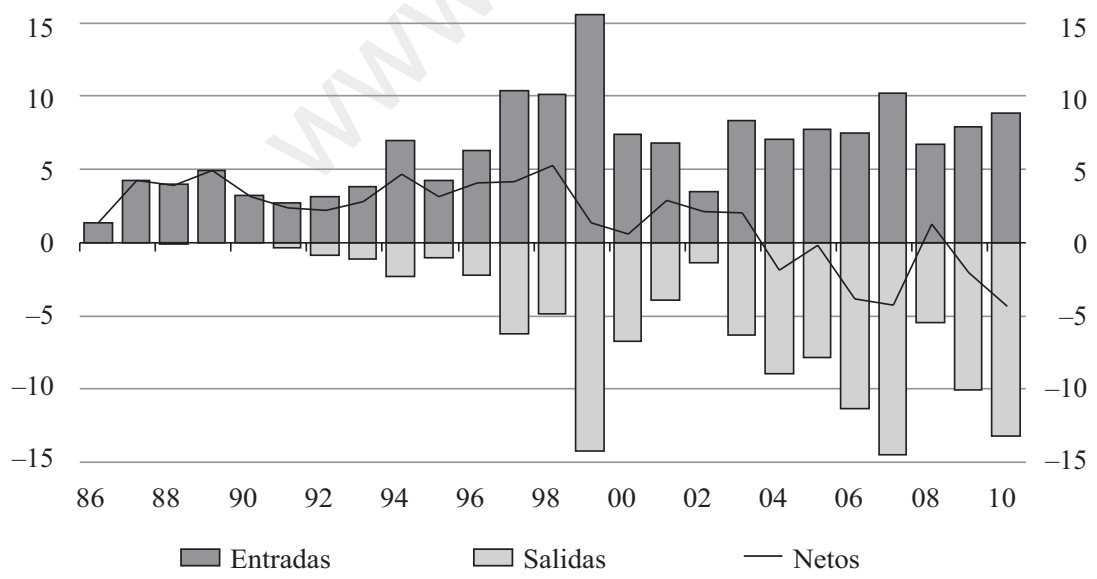

* Hasta 1995 corresponden a la inversión extranjera directa y de cartera, del exterior y hacia el exterior, de la cuenta capital (salvo reservas) de la Balanza de Pagos. Desde 1996 corresponden a los activos y pasivos de los flujos de la cuenta financiera (excluyendo activos de reserva).

Fuente: Banco Central de Chile. 
que se paga hoy por un papel reajustable del Banco Central es algo menos de la mitad de la que se pagaba en los noventa (Gráfico $\mathrm{N}^{\circ} 11$ ). Es probable que la oportunidad de retornos altos de corto plazo, que usualmente se asocian con las entradas masivas de este tipo de capitales, hoy ya no sean del todo evidentes en nuestra economía.

La posibilidad de que mayores flujos de capitales den paso a un crecimiento poco saludable del crédito es otra fuente de preocupación. Los datos no muestran por ahora que el crédito esté creciendo a tasas elevadas. Estas son, de hecho, menores que las que se observaron en los noventa y a las que se aprecian en otras economías emergentes en las que sí se han aplicado medidas para controlar el ingreso de capitales (Gráfico $\mathrm{N}^{\mathrm{o}}$ 12). En todo caso, es importante monitorear la situación, pues flujos excesivos pueden incubar fragilidades financieras y dar origen a ciclos económicos más exacerbados, en cuyo caso podría ser necesario revisar las regulaciones financieras para evitar costosos desbalances.

GRÁFICO No 11: TASA DE INTERÉS REAL DE LARGO PLAZO

(Porcentaje)

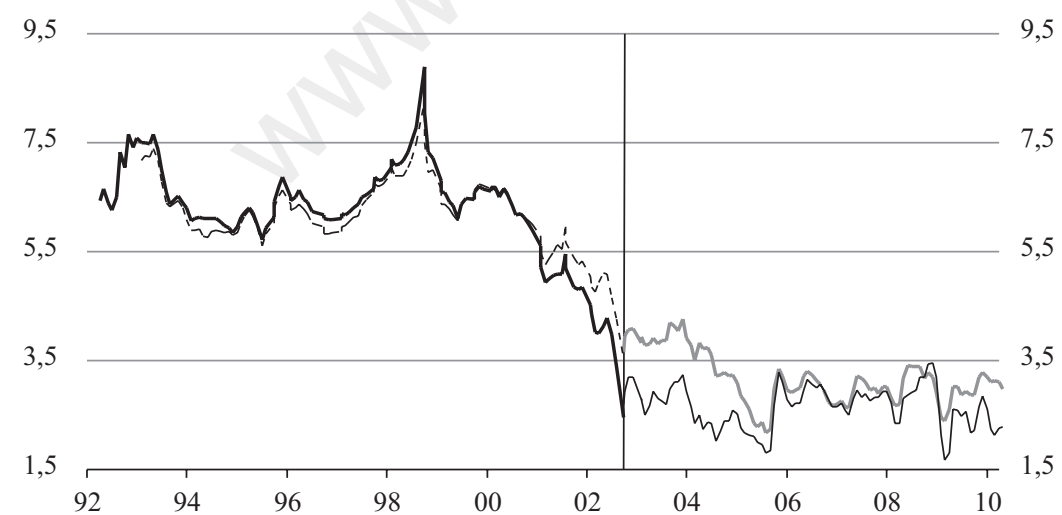

— PRC 8 años $^{1} \quad$-.. PRC 20 años $^{1} \quad$ - BCU 10 años $^{2} \quad$ - BCU 5 años ${ }^{2}$

${ }^{1}$ Los PRC son bonos en UF del BCCh que tienen pagos semestrales iguales (a excepción del último), que pueden incluir tanto pagos de intereses como de capital.

${ }^{2}$ El BCU es un bono emitido en UF, una unidad de reajuste por inflación.

Fuente: Banco Central de Chile. 
GRÁFICO N ${ }^{\circ}$ 12: COLOCACIONES BANCARIAS AL SECTOR PRIVADO

(Variación anual, porcentaje)

\section{Chile}

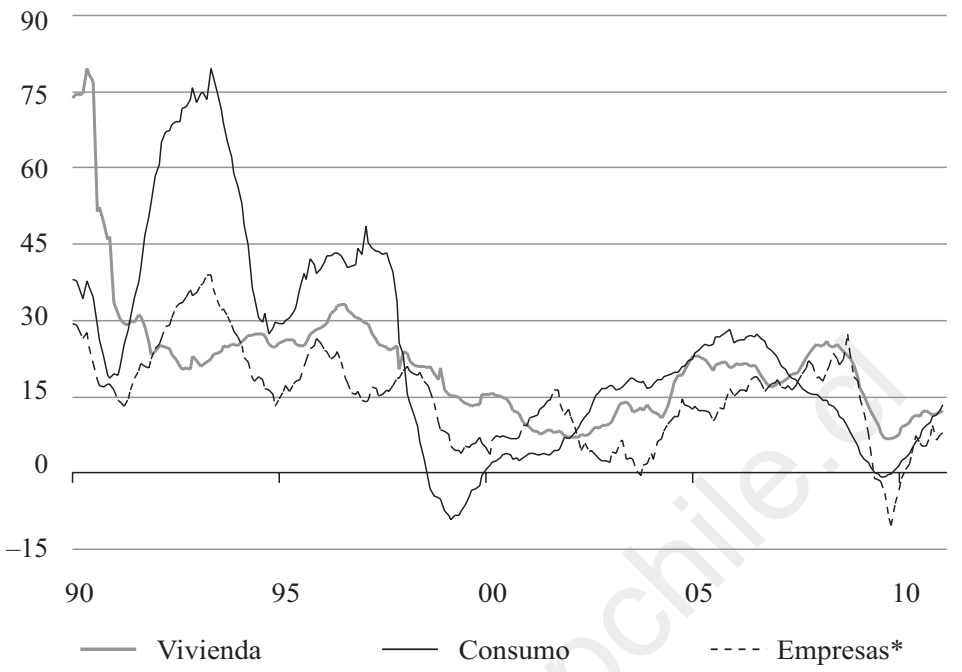

Economías emergentes

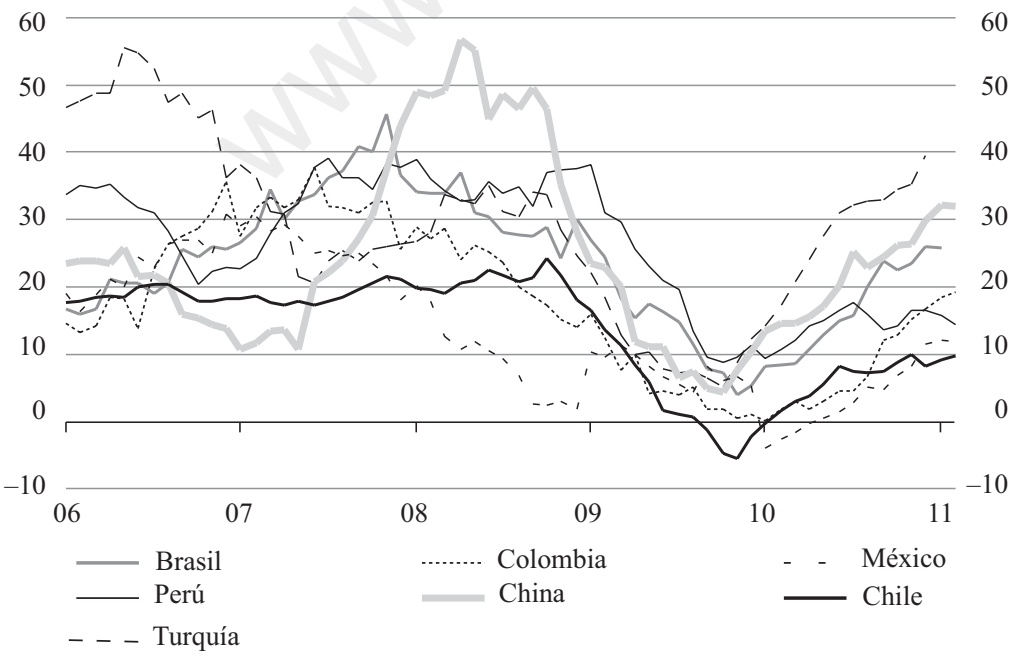

* Corresponden a la suma de los créditos comerciales y de comercio exterior.

Fuentes: Bancos centrales de cada país, Fondo Monetario Internacional y Superintendencia de Bancos e Instituciones Financieras. 


\section{Decisiones recientes de política monetaria}

El escenario delineado en el último Informe de Política Monetaria (IPoM) contempla que en los trimestres venideros la economía nacional mantendrá un ritmo de crecimiento alineado con su potencial. Esto permitirá que la tendencia inflacionaria, hoy en niveles acotados, converja y se mantenga en torno a la meta de 3 por ciento en los próximos trimestres. Para lograr este objetivo, hemos retirado estímulo monetario, acercando la Tasa de Política Monetaria (TPM) a un rango neutral.

Si bien este es el escenario base, en el IPoM también se señaló que los riesgos para la inflación (y el crecimiento) estaban sesgados al alza. En el caso de la inflación, basado en la conjunción de shocks adversos de oferta en energía y alimentos, del cierre de las brechas de capacidad y de un elevado dinamismo de la demanda interna.

Algunos de estos riesgos se han atenuado. Las expectativas inflacionarias privadas se han moderado, de modo coherente con los ajustes de la TPM y la reciente baja en los precios del crudo y otras materias primas (Gráfico $\mathrm{N}^{\mathrm{o}} 13$ ). De todas formas, los mercados de materias primas se mantienen volátiles. Por ello, es temprano para evaluar en qué nivel se asentarán los precios internacionales. Del mismo modo, tampoco se puede descartar que continúen los traspasos de las alzas previas de los precios internacionales sobre los precios internos, particularmente en el caso de alimentos.

Otros riesgos no han mostrado cambios relevantes. Los antecedentes recientes confirman un escenario de alto dinamismo de la demanda interna, particularmente del consumo, y el empleo (Gráfico $\mathrm{N}^{\circ} 14$ ). También se observa una aceleración del crecimiento de los salarios y una rápida recuperación del crédito. La economía nacional crece con fuerza y las holguras de capacidad se han cerrado. No obstante, aún es temprano para señalar que la economía esté sobrecalentada. De hecho, los distintos indicadores de inflación subyacente siguen en niveles por debajo de 3 por ciento (Gráfico $\mathrm{N}^{\circ} 15$ ). La actividad se encuentra cerca de su nivel de plena capacidad y, al igual que en el resto de las economías emergentes, los excesos de demanda interna se están redirigiendo hacia las importaciones. La cuenta corriente se mantiene superavitaria, en gran parte por los favorables precios de las exportaciones, pero también como fruto de volúmenes de ventas al exterior que crecen. Por lo demás, la po- 
GRÁFICO No 13

Expectativas de inflación: EEE y EOF* (Porcentaje)

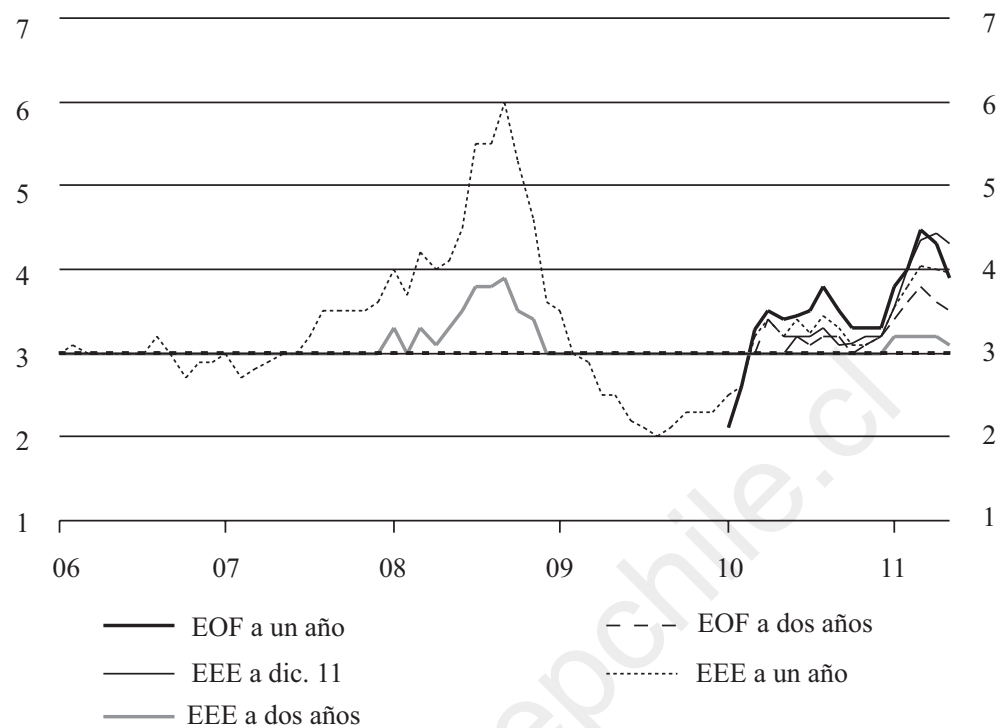

Compensación inflacionaria forward promedio a partir de tasas swap (Promedio móvil semanal, porcentaje)

7 7

6

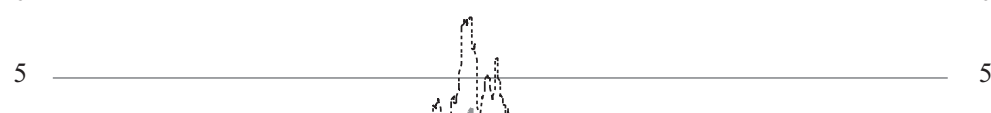

4

3

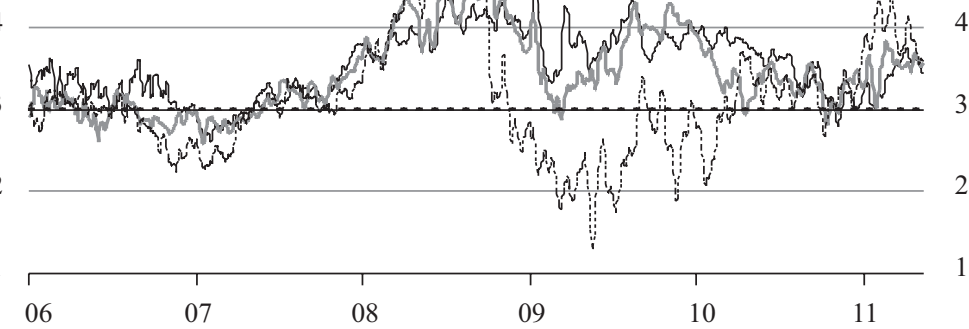

1 en 1

3 en 2 5 en 5

* Para la EOF se considera la encuesta de la primera quincena de cada mes.

Fuente: Banco Central de Chile. 
GRÁFICO No 14

Ventas del comercio minorista y de autos nuevos ${ }^{1,2}$ (Índice $2003=100$ )

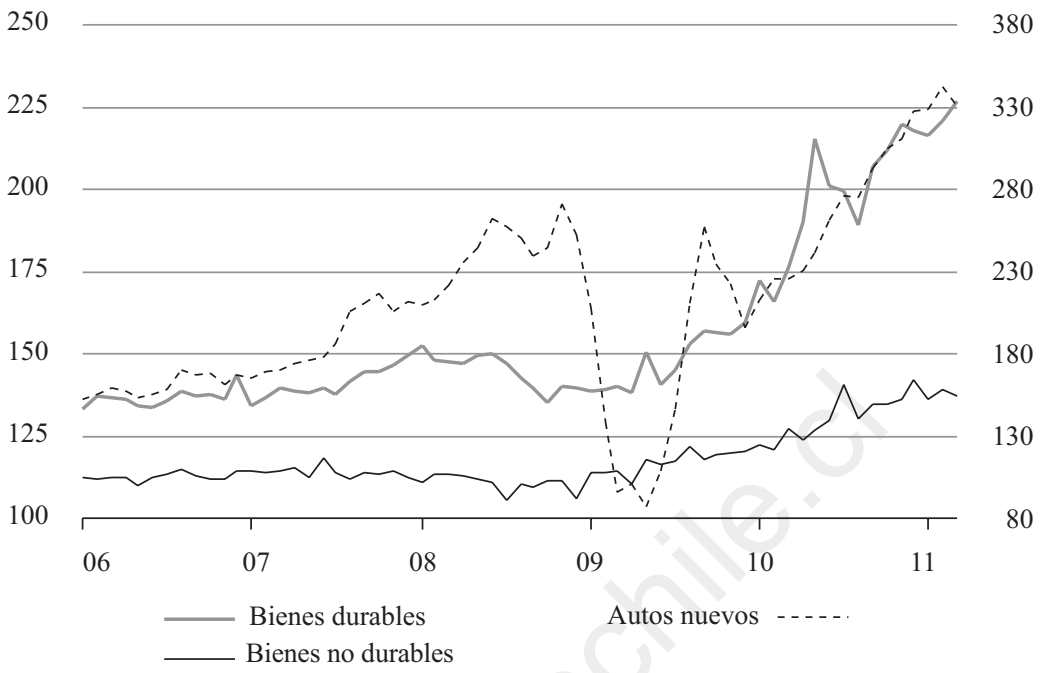

Mercado laboral $^{3}$ (Porcentaje; millones de personas)

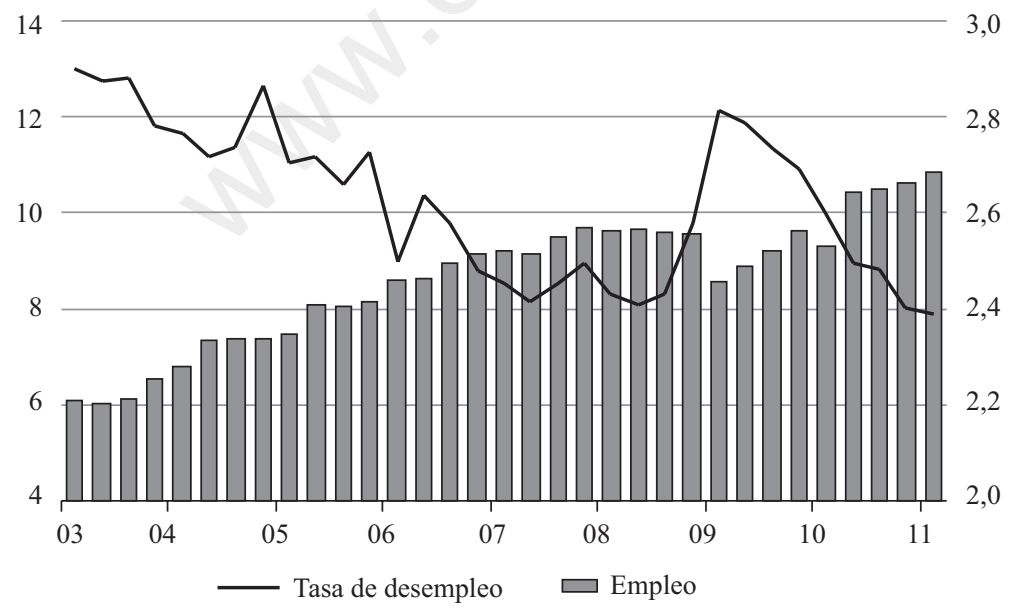

${ }^{1}$ Series desestacionalizadas.

${ }^{2}$ Vendidas en el trimestre móvil.

${ }^{3}$ Considera Encuesta de Empleo y Desempleo para el Gran Santiago de la Universidad de Chile. Series desestacionalizadas.

Fuentes: Asociación Nacional Automotriz de Chile, Banco Central de Chile, Cámara Nacional de Comercio y Universidad de Chile. 
GRÁFICO N ${ }^{\circ}$ 15: INDICADORES DE INFLACIÓN

(Variación anual, porcentaje)

12

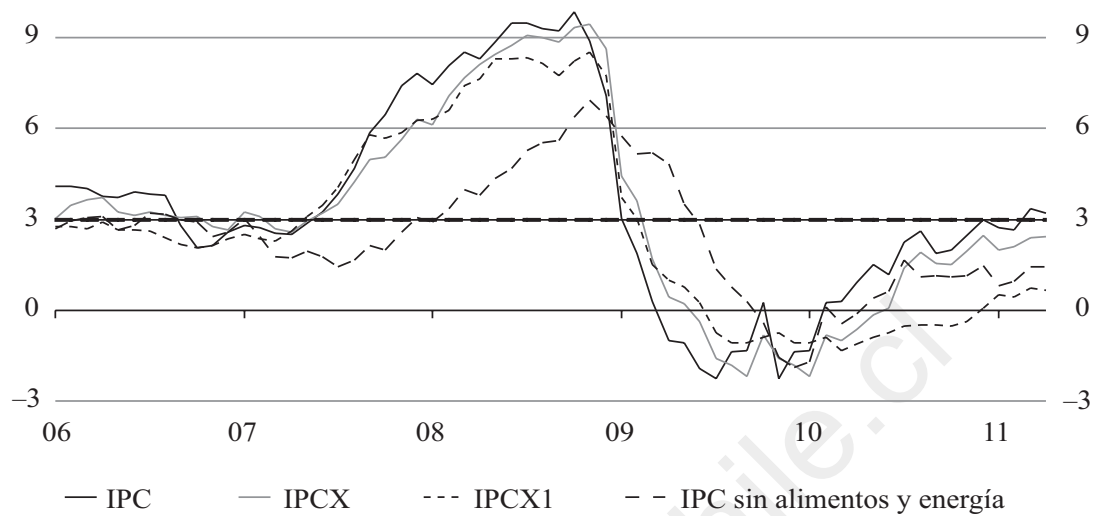

Fuentes: Banco Central de Chile e Instituto Nacional de Estadísticas.

lítica monetaria actúa con rezagos, por lo que es probable que aún no se aprecien plenamente los efectos del incremento de 450 puntos base que ha tenido la TPM desde junio del año pasado. Los datos que recibamos en los próximos meses nos darán una mayor sensibilidad de la magnitud de estos efectos.

Más allá de todo lo anterior, las negativas implicancias de la concreción de estos riesgos llevaron a acelerar el ritmo de normalización de la política monetaria en los últimos meses. De hecho, la semana pasada elevamos la TPM en 50 puntos base, hasta 5 por ciento. Aunque la mediana de las expectativas de mercado anticipaba un alza algo menor, actuamos en forma preventiva para contener el dinamismo de la demanda interna y la propagación de los shocks adversos de oferta. Ahora que la TPM ya se ubica en 5 por ciento, se acerca al rango de valores que históricamente han sido considerados como neutrales. En todo caso, el grado de incertidumbre sobre la tasa de interés neutral es elevado.

Existen muchas definiciones y metodologías para determinar lo que sería una tasa de interés coherente con la inflación en su meta y la economía operando a plena capacidad. Aunque esta no es la oportunidad para entrar en una larga discusión sobre el nivel de la tasa neutral, 
me parece importante hacer algunas observaciones. Por un lado, la tasa neutral no es un número fijo. Varía en la medida que el estado de la economía se modifica e incluso es posible que en el corto plazo fluctúe. Por otro lado, la tasa neutral en una economía abierta depende no solo de factores internos, como su tasa de crecimiento de largo plazo, sino que también del entorno externo. El mundo está atravesando por un período de tasas de interés bajas y es probable que en el corto plazo la tasa de interés neutral esté algo por debajo de lo que indican estimaciones previas (Gráfico N $\left.\mathrm{N}^{\mathrm{o}} 16\right)$.

En todo caso, también quiero destacar que el objetivo de la conducción de la política monetaria no es alcanzar una tasa neutral, cualquiera sea su nivel. La tasa de política monetaria (TPM) fluctúa en torno a esta tasa neutral, de modo que el impulso monetario sea coherente con el logro de la meta. Así, tal como hay períodos en los cuales la TPM se

GRÁFICO N ${ }^{\circ}$ 16: $\quad$ MUNDO: TPM Y EXPECTATIVAS ${ }^{1}$

(Porcentaje)

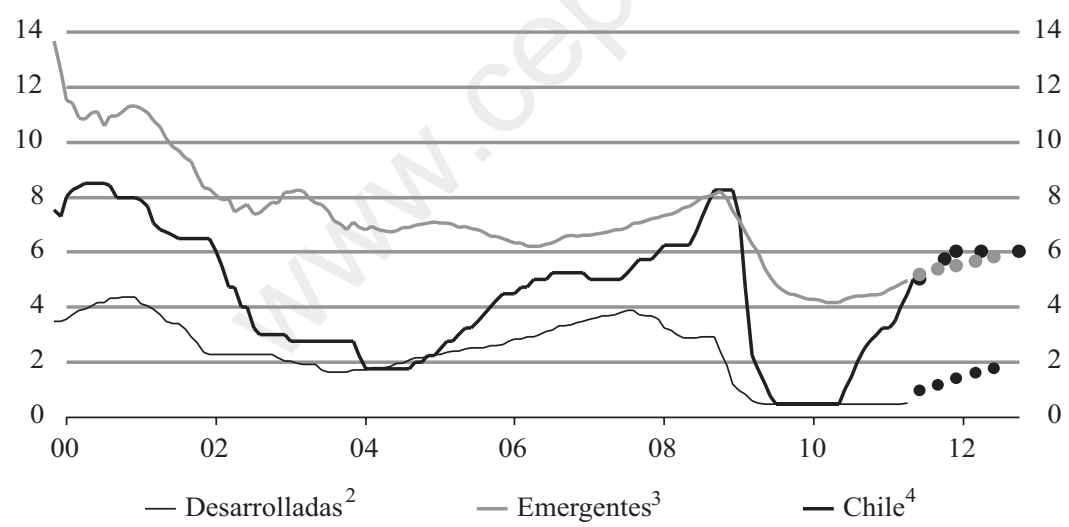

${ }^{1}$ Líneas continuas corresponden a un promedio simple de las tasas de referencia de cada conjunto de países. Puntos consideran la mediana de la encuesta de analistas de Bloomberg sobre la TPM esperada. Para Chile considera la EEE.

2 Incluye Canadá, Estados Unidos, Noruega, Japón, Reino Unido, Suecia, Suiza y Zona Euro.

${ }^{3}$ Incluye Brasil, Colombia, China, Hungría, México, Perú, Polonia, Rep. Checa, Rep. Corea y Sudáfrica.

${ }^{4}$ Datos anteriores a la nominalización de la tasa de referencia (agosto del 2001), consideran la tasa interbancaria a un día en términos reales más la inflación del IPC.

Fuentes: Banco Central de Chile, Bancos centrales de los respectivos países, Bloomberg y Fondo Monetario Internacional. 
ubica por debajo de la neutral, en otras ocasiones lo hará por encima. Esto es coherente con el hecho de que la actividad económica fluctúa en torno a su nivel de plena capacidad, pasando de períodos de subutilización a otros de sobreutilización de capacidad. En suma, cuál es el nivel máximo al que llegará la TPM y en qué momento llegaremos a él en el actual ciclo, es algo que iremos analizando en el Consejo con el correr del tiempo.

En lo que va corrido del año ya se acumuló un aumento de 200 puntos base en la TPM y estimamos que serán necesarios aumentos adicionales. La magnitud y oportunidad de estos incrementos dependerá de la evolución de los datos, de los riesgos y de sus implicancias para las perspectivas inflacionarias, tomando en cuenta los rezagos con que opera la política monetaria. Por esto, no se puede descartar ningún escenario. Es probable que en las próximas reuniones la magnitud del ajuste aminore e incluso pueda haber pausas. Del mismo modo, aunque su probabilidad hoy es menor, también es factible que el ritmo reciente se mantenga si los riesgos inflacionarios así lo ameritan. En todo caso, parece existir un consenso en las expectativas de mercado en cuanto a que en el futuro se requiere de ajustes de menor cuantía. De hecho, la mayor parte de los pronósticos ubican la TPM en cifras en torno a 6 por ciento para fines de este año (Gráfico $\left.\mathrm{N}^{\circ} 17\right)$.

(Porcentaje)

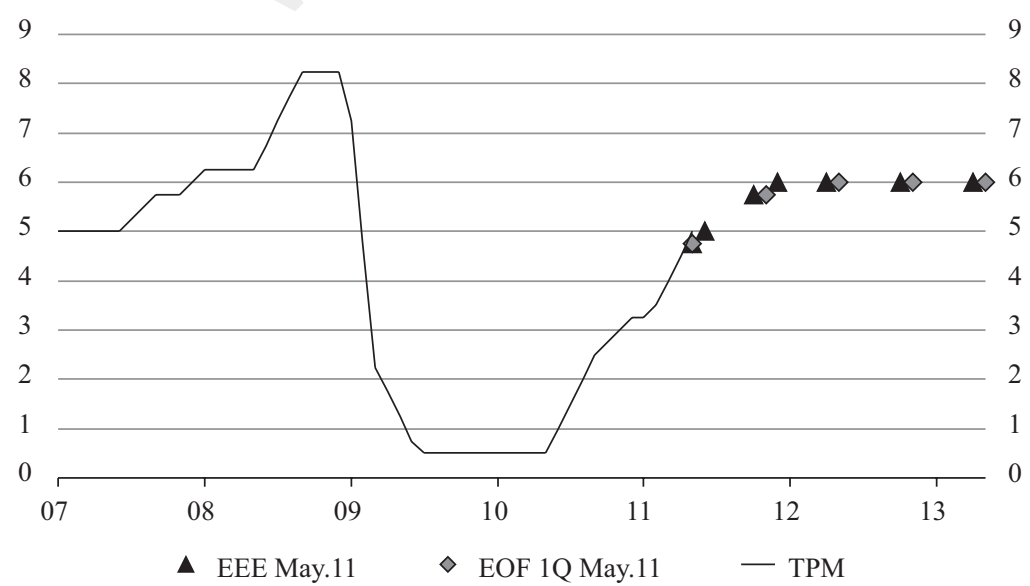

Fuente: Banco Central de Chile. 


\section{Conclusiones}

Los últimos años han sido de alta complejidad, probablemente las políticas económicas han enfrentado los mayores desafíos en décadas. Los vaivenes en la actividad económica, la inflación y las expectativas, entre muchas otras variables, han sido inusualmente marcados.

El marco de políticas macroeconómicas chileno ha dado prueba de su flexibilidad y efectividad, logrando mitigar y superar los efectos de la crisis mundial. Hoy encaramos nuevos e importantes desafíos. La economía debe mantenerse en una senda de crecimiento congruente con su capacidad y la tendencia inflacionaria debe ser coherente con su meta. Sumado a ello, el desigual ritmo de crecimiento entre el mundo desarrollado y emergente nos pone frente a tensiones cambiarias que nos imponen nuevas pruebas.

Enfrentamos un escenario complejo. La inflación ha evolucionado acorde con la meta, aunque, como hemos venido señalando, puede sobrepasar el máximo de nuestro rango de tolerancia debido a la fuerza del alza de los precios internacionales del petróleo y de los alimentos.

Es importante limitar la propagación indeseada de estos shocks a otros precios. Por ello, el Banco ha actuado rápidamente, previniendo que no se incuben presiones inflacionarias que puedan comprometer el logro de una inflación baja y estable. Hemos retirado el fuerte impulso que traía la política monetaria en el 2009 y 2010. Estimamos que la TPM deberá seguir aumentando en los próximos meses, pero la magnitud y oportunidad de esos aumentos dependerá de las implicancias de la información que recibamos, sin descartar a priori ningún escenario. Como siempre, el Consejo guiará sus decisiones para lograr que la inflación se mantenga baja y estable, que es el mayor aporte que el Banco Central puede realizar al desarrollo del país.

\section{POST SCRIPTUM}

Desde mayo de este año hasta hoy (14 de octubre) ha habido cambios muy importantes en la economía mundial. La economía de los Estados Unidos se ha debilitado y las proyecciones de crecimiento para el 2011-12 se han corregido a la baja. Lo que originalmente se pensó podría ser un soft patch, a raíz del alza del precio del petróleo y las dis- 
rupciones en la cadena de producción generados por el terremoto en Japón, resultó ser una desaceleración más prolongada. El alto desempleo y endeudamiento de los hogares ha causado un consumo débil, a lo que se agregan las limitaciones a la política fiscal acordadas tras la elevación del límite de deuda del gobierno estadounidense. Los espacios para una política monetaria más expansiva también son escasos, dado el bajo nivel de tasas de interés, y solo medidas no convencionales, de acotada efectividad, están disponibles.

No obstante, el deterioro más relevante es el agravamiento de los problemas de deuda soberana en Europa. Lo que unos meses atrás estaba circunscrito a las economías periféricas en problemas (Grecia, Irlanda y Portugal), a principios de agosto se extendió a economías sistémicas de la eurozona, España e Italia. Esto ha tenido severas repercusiones financieras, con alzas sustanciales de las primas de riesgo y se ha transmitido al mundo entero a través de cambios en los precios de los activos, en especial por una caída de la mayoría de los mercados accionarios. La crisis está en pleno desarrollo y su resolución es incierta. La incapacidad de encontrar una solución definitiva y sostenible genera un panorama de alta incertidumbre. A diferencia de lo que se podía prever en mayo de este año, tal como se discute en el documento, hoy no es descartable una solución desordenada a los problemas de Grecia, la cual podría terminar en un default de su deuda soberana y, en un caso extremo, en una salida del euro. Lo que mantiene el férreo compromiso de resolver el problema en la eurozona, sin que esto provoque la salida de un país de la unión monetaria, son los riesgos de crisis financiera que una acción de este tipo pudiera traer. Por ello, las autoridades se han enfocado en cómo aislar a la eurozona de problemas de países específicos, cómo recapitalizar los bancos para proteger sus sistemas financieros y cómo resolver el caso particular de Grecia. Es difícil construir una solución definitiva para Grecia sin tener los cortafuegos para el resto de la región.

El deterioro de la situación económica en las economías desarrolladas ha repercutido también en un significativo descenso en el precio de las materias primas. Esto ha quitado presión sobre la inflación en las economías emergentes, lo que unido a un panorama de debilidad en el mundo desarrollado también hace que los riesgos de sobrecalentamiento disminuyan. Con todo, el mayor riesgo para las economías emergentes hoy es hasta qué punto se puede sostener el crecimiento con una parte 
importante del mundo en una fase de muy lenta recuperación, donde ni siquiera es descartable un deterioro adicional.

También se ha observado un debilitamiento de las monedas de las economías emergentes, explicado por la caída de los términos de intercambio y el aumento de la aversión al riesgo en el mundo. El peso chileno también ha sido afectado. Los vaivenes de nuestra moneda han sido importantes, con una depreciación relevante en un comienzo, que luego se ha atenuado. No se puede descartar que nuevos focos de turbulencias financieras internacionales provoquen nuevos episodios de volatilidad en el tipo de cambio. El esquema de flotación cambiaria permite que nuestra economía se ajuste a las fluctuaciones internacionales, lo que mitiga los efectos sobre la actividad y el empleo. Sus consecuencias inflacionarias se encuentran limitadas por el mismo esquema de flotación y por el hecho que ha sido acompañada de una caída de los precios de las materias primas.

En la actualidad, la economía mundial depende menos de las economías desarrolladas que hace un par de décadas. En 1990, las economías desarrolladas representaban 69 por ciento de la actividad mundial medida a paridad de poder de compra, hoy solo son el 51 por ciento, gracias al vigoroso proceso de crecimiento de las economías emergentes. En Chile, en 1990 nuestro comercio con los países desarrollados representaba 80 por ciento del total. Hoy es solo el 49 por ciento. Somos mucho más integrados con las economías emergentes, lo que constituye un factor fundamental para reducir el impacto del deterioro económico de los países desarrollados.

La actividad económica en Chile ha seguido moderándose en los últimos meses. El rápido crecimiento del primer semestre se debería normalizar y converger hacia una expansión más coherente con nuestros niveles de crecimiento tendencial, en torno a 5 por ciento. Esto garantiza estabilidad en la inflación y un panorama de crecimiento sostenible, que no se vea interrumpido por excesos.

Los registros inflacionarios han sido menores a los esperados, como resultado de una política monetaria que se ha anticipado a potenciales efectos de propagación que pudieran poner en riesgo la meta, de un menor traspaso de los aumentos de los precios internacionales a la economía local y del escenario menos negativo por el lado del precio de las materias primas. Todo lo anterior, junto con las menores expectativas de crecimiento en las economías desarrolladas, se ha traducido 
en una caída de las expectativas inflacionarias, elemento central en el control de la inflación.

El cambio de las perspectivas inflacionarias y de actividad global ha producido, como debiera ser, un cambio en la política monetaria. Hace unos meses se esperaba que el proceso de normalización de la política monetaria continuara durante este año, para llevar la Tasa de Política Monetaria (TPM) a niveles cercanos al 6 por ciento en diciembre. Dicha perspectiva ha cambiado; en las reuniones de política monetaria de julio, agosto, septiembre y octubre se mantuvo la tasa en 5,25 por ciento. En agosto, días después del severo deterioro de la economía global, se quitó el sesgo alcista de la política monetaria, dejando una instancia neutral. Más aún, tal como comunicamos en nuestro último Informe de Política Monetaria, suponer que la tasa se mantendrá constante por el resto del año es coherente con el logro de la meta de inflación. Incluso, tras nuestra Reunión de octubre comunicamos que la profundización de las tendencias observadas en la economía internacional podría configurar un entorno externo más adverso que el contemplado en el escenario base del Informe de Política Monetaria de septiembre, con posibles consecuencias para el crecimiento y la inflación en Chile, así como para la orientación de la política monetaria. Ello indica nuestro compromiso con el manejo de una política monetaria flexible y capaz de mitigar el impacto de escenarios internacionales adversos.

Como ya lo demostramos en el pasado, hemos conducido la política monetaria con suficiente flexibilidad para poder adoptar las decisiones que sean necesarias a fin de cumplir con la meta de inflación. Ya durante la crisis del 2008-09 se demostró que este esquema permite acomodarse adecuadamente para mitigar los efectos de un escenario internacional adverso.

El mundo se encuentra en una coyuntura particularmente compleja. La incertidumbre es elevada y una economía abierta al mundo, como lo es Chile, no puede estar inmune a los eventos externos. No obstante, hemos construido un esquema de políticas macroeconómicas que nos permiten como nunca en nuestra historia enfrentar de mejor manera escenarios internacionales muy adversos. 